\title{
Haptoglobin DNA polymorphism in subterranean mole rats of the Spalax ehrenbergi superspecies in Israel
}

\author{
Eviatar Nevo, \\ Rachel Ben-Shlomo and \\ Nabuyo Maeda*
}

\author{
Institute of Evolution, University of Haifa, \\ Mt. Carmel, Haifa 31999, Israel. \\ * Laboratory of Genetics, University of Wisconsin, \\ Madison, Wisconsin 53706.
}

\begin{abstract}
We analyzed the genetic diversity and environmental correlates of the haptoglobin $(H p)$ gene by RFLP analysis of 121 subterranean mole rats, comprising 13 populations belonging to the 4 chromosomal species $(2 n=52,54,58$ and 60$)$ of the actively speciating Spalax ehrenbergi superspecies in Israel. The following results were indicated: (i) Out of the six restriction enzymes we tested, we found polymorphism only in TaqI, with three allelic fragments, and described their geographic patterning. (ii) Genetic diversity of $H p$ was highest in the centre of the range. (iii) The two major alleles showed high significant and opposite correlation with humidity. (iv) Genetic differentiation analysis indicated that 40 per cent of the $H p$ variation was within, and 60 per cent between populations. We conclude that climatic selection plays an important role in haptoglobin genetic differentiation.
\end{abstract}

\section{INTRODUCTION}

Haptoglobin, the hemoglobin binding protein of plasma, contains two $\alpha$ and two $\beta$ chains that are synthesized colinearly as a single precursor polypeptide and processed post-translationally (Yang et al., 1983; Raugei et al., 1983; Van der Straten et al., 1983). The evolution of multigene families, exemplified by human haptoglobin genes has been reviewed by Maeda and Smithies (1986). The haptoglobin gene family is relatively simple, and its evolutionary history is sufficiently recent, postmammalian radiation the duplication of the $H p$ gene occurred at least 30 million years ago. The inherited variations in humans are a consequence of the three common, autosomal alleles $H p^{1 \mathrm{~F}}, H p^{1 \mathrm{~S}}$ and $H p^{2}$ which code for different $\alpha$ chains but identical $\beta$ chains. At the protein levels of subterranean mole rats of the Spalax ehrenbergi superspecies in Israel (reviewed in Nevo, 1982, 1985, $1986 a, b, 1989$ ), haptoglobin proved monomorphic in blood samples of 449 individuals from 24 populations of the four chromosomal species (Nevo and Cleve, 1978) across the Spalax range in Israel (fig. 1). Here, we show that the DNA of the $S$. ehrenbergi superspecies is polymorphic, either within or near the $H p$ gene, and that the polymorphism is correlated with ecological heterogeneity.
MATERIAL AND METHODS

\section{Sampling}

We tested DNA polymorphisms of the haptoglobin gene in 121 mole rats collected during the winters (November-February) of 1984-86, comprising 13 populations and four chromosomal species of the $S$. ehrenbergi superspecies in Israel (see table 1 and fig. 1). Live animals were caught in their underground runways in the field, brought to the laboratory and dissected. Tissues were instantly frozen in liquid nitrogen and then stored at $-80^{\circ} \mathrm{C}$.

\section{DNA extraction, digestion and blotting}

High molecular weight genomic DNA was extracted from the kidneys, following Holland (1983). Five different six-base recognition endonucleases (EcoRI, HindIII, Bst EII, Kpn I, BamHI) and one four-base recognition enzyme ( $T a q \mathrm{I})$ were used for digestion. Twenty-five micrograms of genomic DNA were incubated over night with 150 units of a given endonuclease, following the conditions recommended by the supplier (BioLabs, New England, USA). Fully digested DNA was precipitated in ethanol, followed by electrophoresis, through both $0 \cdot 6$, and 1 per cent agarose gels for 


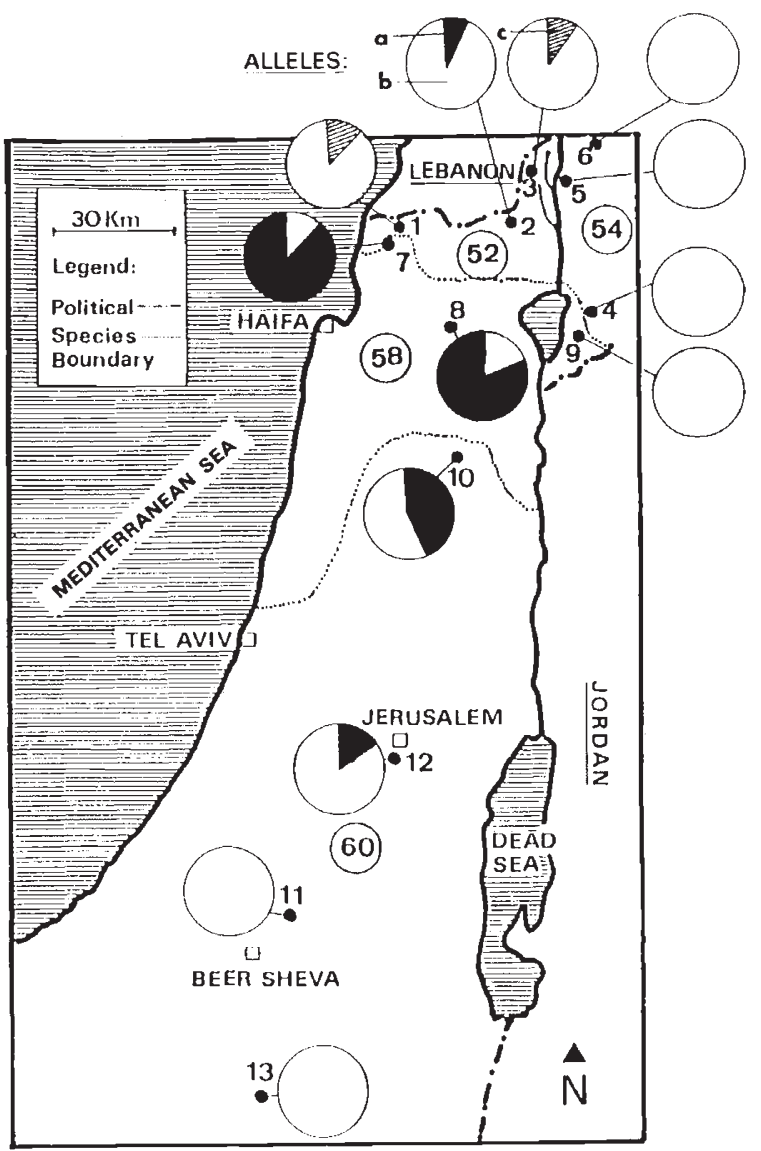

Figure 1. Geographical distribution of the 13 populations and four chromosomal species of the Spalax ehrenbergi superspecies in Israel. The pie diagrams show in each population, the proportion of the three $H p$ alleles: $a, b$ and $c$.

16 hours at $30 \mathrm{~V}$. DNA was denatured and transferred to either nitrocellulose or nylon (Hybond-N, Amersham, UK) filters following Southern (1975).

\section{Hybridization}

We used a plasmid DNA as a vector containing an insert to detect the haptoglobin gene. The insert was $650 \mathrm{bp} \mathrm{Bam} \mathrm{HI/HindIII} \mathrm{fragment} \mathrm{of} \mathrm{the} \beta$ chain coding region of the human haptoglobin gene, $H p^{2}$ cDNA (Maeda et al., 1984). The insert used as a probe corresponds to exon 5 of the human gene, which is $6.5 \mathrm{~kb}$ long. If the TaqI polymorphism described later is due to site difference, the polymorphic site should be anywhere within $20 \mathrm{~kb}$ of DNA. The probability of being within the gene $(6.5 \mathrm{~kb})$ is then about 50 per cent. The $\alpha$ and $\beta$ chains of haptoglobin are colinearly transcribed and processed post-translationally. The $\beta$ chain is more conserved during evolution (Kurovsky et al., 1976) therefore, we used this probe to detect the mole rat gene. We transformed about $0.01 \mathrm{mg}$ of the probe to $E$. coli, HB 101 strain. The vector was pAT153 and the plasmid was ampicillin resistant.

The DNA fragment was radiolabelled by the random prime method of Feinberg and Voglestein (1984) overnight at room temperature. Hybridization of ${ }^{32} \mathrm{P}$-labeled probes with the DNA on filters was performed in 50 per cent formamide solution overnight at $42^{\circ} \mathrm{C}$, following the filter manufacturer's (Amersham, UK) recommended methods. Filters were washed at stringency conditions of $2 \times$ SSPE and $0 \cdot 1$ per cent SDS at $60^{\circ} \mathrm{C}$. We then autoradiographed at $-70^{\circ} \mathrm{C}$, using two intensifying screens (Kodak rapid or super rapid).

\section{Data analysis}

The data were analyzed as allelic fragment frequencies, by scoring the bands directly from the autoradiograph, thus identifying directly the homozygous and heterozygous genotypes. Observed heterozygosity $H$ was calculated by directly scoring from the gels the proportion of heterozygous individuals per population and per species, followed by the expected heterozygosity, or gene diversity under panmixia $(\mathrm{He})$. We ran Spearman rank correlations of allele frequencies, $H$ and $H e$ with several climatic variables, and generated genetic distances (Nei, 1972) and genetic differentiation (Nei, 1973) estimates.

\section{RESULTS}

The hybridization results indicated that there is one $\beta$ chain of haptoglobin gene in each of the four chromosomal species of $S$. ehrenbergi, as was previously shown at the protein level (Nevo and Cleve, 1978). Out of six restriction enzymes tested (EcoRI, HindIII, BstEII, KpnI, Bam HI, and TaqI), we found polymorphism only in the TaqI four-base recognition enzyme. Digestion with EcoRI resulted in one monomorphic fragment of about $10 \cdot 15 \mathrm{~kb}$. Bst EII showed a monomorphic fragment of $3 \mathrm{~kb}$. KpnI has restriction site in the gene resulting in two monomorphic fragments, one of $11.5 \mathrm{~kb}$ and the other of $1.65 \mathrm{~kb}$. Bam HI resulted in a monomorphic fragment of $8 \cdot 15 \mathrm{~kb}$. We obtained scorable TaqI polymorphism with three allelic fragments, henceforward called alleles, in the $H p^{2} \beta$ fragment: a, b and c. We also observed $\mathrm{ab}$ and $\mathrm{bc}$ heterozygotes (table 1 and for heterozygote $a b$ see fig. 2). The largest allelic fragment, a 


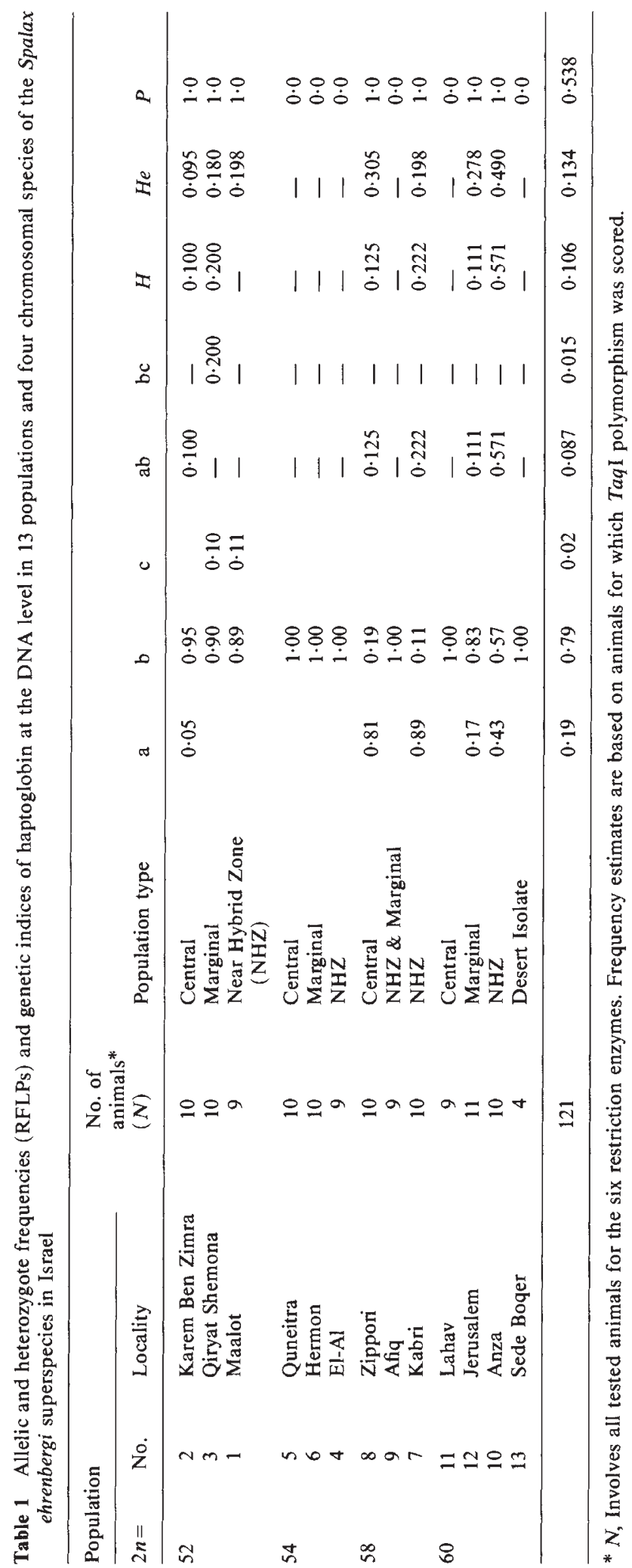




\section{융 웅}

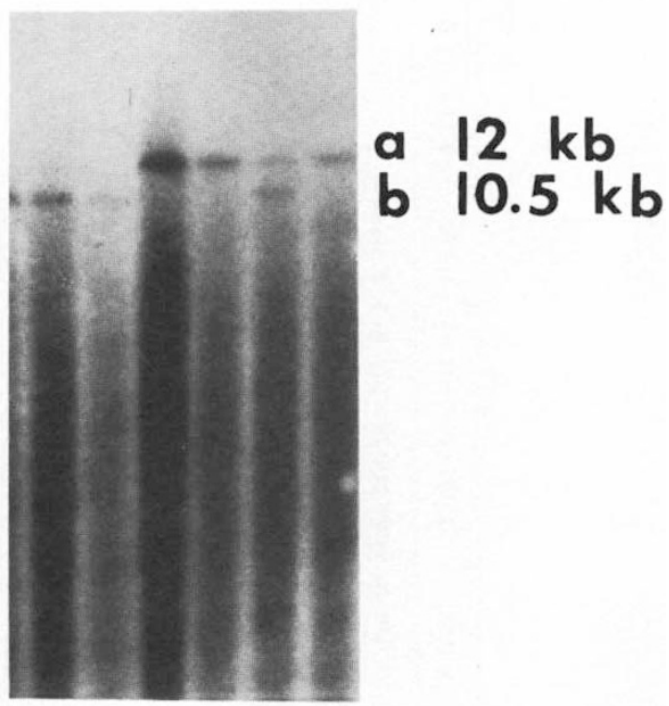

Figure 2. Allelic pattern of Hp TaqI polymorphism in Spalax ehrenbergi, involving the two alleles $a$ and $b$ and the heterozygote $a b$.

is $12 \mathrm{~kb}$; $\mathrm{b}$ is $10.5 \mathrm{~kb}$; and $\mathrm{c}$ is $8.4 \mathrm{~kb}$ long. The probe we used to detect the TaqI polymorphism corresponds to exon 5 of the human gene. Assuming that the length of the haptoglobin gene in mole rats is similar in size to that in humans $(6.5 \mathrm{~kb})$, the different alleles derive presumably from mutations either inside or very near to the $H p$ gene.

The frequencies of alleles, observed heterozygosity, $H$, and expected heterozygosity, $\mathrm{He}$, are given in table 1 , and allele frequencies in the pie diagrams of fig. 1 . The following results were indi. cated.

(1) Allele b is the major allele appearing in all 13 populations studied. It is monomorphic in all populations of the $2 n=54$ chromosomal species in the Golan Heights (populations 4, $5,6)$; in the $2 n=58$ population of the Golan Heights (population 9); as well as, in the southern central populations of $2 n=60$ (population 11) and in the northern Negev desert isolated population of Sede Boqer (population 13).

(2) Allele a appears in high frequencies in two populations of $2 n=58$ ( 7 and 8 ) and in the northernmost population of $2 n=60 \quad(10)$, decreasing in frequency, possibly in a clinal pattern, toward Jerusalem (population 12 of $2 n=60)$. The main range of the allele is in the warm and humid ranges of $2 n=58$. It decreases in frequency toward the northeast semiarid $(2 n=54)$ and south arid $(2 n=60)$ climatic regimes.

(3) Allele c appears in low frequency in only two populations of the $2 n=52$ chromosomal species (1 and 3 ).

(4) All genetic indices of diversity, observed heterozygosity, $H$, genic diversity, $\mathrm{He}$, and polymorphism, $P 1$ per cent, are highest in the centre of the range of the $S$. ehrenbergi superspecies (populations 7 and 8 of $2 n=58$ and population No. 10 of $2 n=60$; see table 1). The highest value of $\mathrm{He}$ is in population No. 10 of the chromosomal species $2 n=60$.

(5) We found high significant and opposite Spearman rank correlations of the largely complementary two major alleles, $a$ and $b$ with the average annual humidity climatic variable, Huan, as follows: Allele a displayed a positive correlation with humidity, $r_{\mathrm{s}}=0 \cdot 64, P=0 \cdot 017$. By contrast, allele $b$ displayed significant negative correlation with humidity: $r_{\mathrm{s}}=-0.85, P<$ $0 \cdot 0005$. Likewise, $H e$ also displayed high significant correlation with annual humidity, $r_{\mathrm{s}}=$ $0 \cdot 79, P<0 \cdot 001$. We found no significant correlations with temperature variables.

(6) A Gst analysis (Nei, 1973) indicated that 40 per cent of the $H p$ variation was within, and 60 per cent between populations.

\section{DISCUSSION}

The geographic variation of the TaqI DNA polymorphism clearly displays nonrandom geographic patterning and ecological correlates. Both genetic diversity and the frequencies of the two major alleles, $a$ and $b$ are highly and significantly correlated complementarily with high humidity index ( $\mathrm{He}$ and allele a) and with high aridity index (allele b). This high and significant correlation of the $\mathrm{Hp}$ alleles and genic diversity with the humidity index, reveals two phenomena: (i) climatic selection appears to maintain either directly or indirectly this $H p$ polymorphism, and (ii) $H p$, like other genetic markers, emphasizes the lack of gene flow, or degree of reproductive isolation between the two chromosomal species $2 n=52$ and 58 . We briefly discuss these two aspects.

Natural selection, primarily climatic selection, appears to determine both phenotypic and genotypic diversities of the $S$. ehrenbergi superspecies (Nevo, 1985, 1986a, b). This conclusion stems from the significant climatic correlations 
with phenotypic variation at the morphological (e.g., size, incisors, pelage colour, brain-size, morphometrics); physiological (e.g., metabolism, water turn-over, thermoregulation, respiration, urine concentration, heart and breathing frequencies, hematocrite and hemoglobin concentrations) and behavioral (e.g., activity, exploration, habitat selection, aggression) levels. Likewise, a series of molecular markers (several allozyme loci, MHC (the major histocompatibility complex), rDNA, aldolases, mtDNA (mitochondrial DNA)) and now haptoglobins, displayed significant ecological correlations, primarily with the humidity or aridity indices. Differential survivorship of the chromosomal species in climatically standardized laboratory environments is clearly determined by their climatic origin (Nevo et al., 1982). All these extensive organismal and molecular correlations, provide a clear testimony that climatic adaptations at all phenotypic and molecular levels are central to the adaptive radiation and speciation of the $S$. ehrenbergi in Israel and vicinity. Individual correlations may suggest spuriousness. Massive correlations at molecular and multiple organismal levels suggest robustness of the overall relationship between organism and environment. In such cases repeated correlations may reflect causations (Nevo et al., 1984). The distribution of the four chromosomal species into four climatic regimes is thus explicable: cool and dry $(2 n=54)$; cool and humid $(2 n=52)$; warm and humid $(2 n=58)$; warm and dry $(2 n=60)$.

\section{Speciation, reproduction isolation and gene flow}

Spalacidae originated on available fossil record (Bruijn, 1984) in the early Miocene, and on evidence derived from DNA-DNA hybridization (Catzeflis et al., 1988) 19 million years ago, but 45 million years ago, based on the amino-acid structure of haemoglobin (Kleinschmidt et al., 1985) and microcomplement fixation of albumin and transferrin (Nevo and Sarich, 1974). However, the $S$. ehrenbergi superspecies in Israel and vicinity is young. DNA-DNA hybridization evidence (Catzeflis et al., 1988) suggests that the S. ehrenbergi superspecies originated in the Early Pleistocene, around $1 \cdot 6 \pm 0.3$ million years ago $(2 n=54)$, and kept speciating stepwise since the Middle Pleistocene. The estimates of evolutionary divergence times of $2 n=58$ and 60 , according to DNA-DNA hybridization are $0 \cdot 2 \pm 0.04$ million years ago (Catzeflis et al., 1988), while allozymic evidence suggests time estimates of 250,000 , for the entire complex, and 70,000 years ago, for the recent speciation event generating, $2 n=60$ (Nevo and Cleve, 1978). The fossil record supports these time estimates. The first fossil remains of Spalax from the Early Pleistocene, Ubeidiya formation, in Israel are dated to 1.4 million years ago (Tchernov, 1987). This Early Pleistocene age parallels that of the suggested origin of $2 n=54$ on molecular grounds. However, the dramatic evolution of spalacids as indicated by the fossil record is Upper Pleistocene (Tchernov, 1968), paralleling the speciation event based on molecular grounds that generated $2 n=58$ and 60 .

Natural hybridization in nature and mateselection in laboratory experiments (reviewed in Nevo, 1985, 1986b), support the evolutionary divergence times, derived from molecular and fossil evidence. Moreover, molecular markers can track the past and present the amount of gene flow across the hybrid zones. Several molecular markers have already indicated that gene flow does not occur, across the $2 n=54-58$ contact zone in the Golan Heights and across the $2 n=52-58$ contact zone between the Upper and Lower Galilee Mountains. These include, in either or both of the two aforementioned hybrid zones, the following markers: rDNA (Suzuki et al., 1987); $m t$ DNA (in preparation); MHC (Ben-Shlomo et al., 1988); aldolases (Nevo et al., 1988). In other words, gene flow does not cross the $2 n=52-58$ and $2 n=54-58$ hybrid zones and if parental types do cross these narrow hybrid zones $(320$ and $750 \mathrm{~m}$ in width; respectively), they are eliminated by natural selection. In the $2 n=54-58$ hybrid zone, the Afiq, $2 n=$ 58 population (No. 9) seems, at least in several markers (rDNA, $H p$ described here), to be similar to the El-Al, $2 n=54$ population (No. 4). Recall that DNA-DNA hybridization indicates that the largest evolutionary divergence time, 1.4 million years ago, is between $2 n=54$ and all the other three chromosomal species (Catzeflis et al., 1988). Therefore, the similarity in several markers in the Golan Heights, between $2 n=54$ and $2 n=58$, appears to be the result of sharing similar dry environments across the southern Golan Heights, rather than due to introgression from $2 n=54$ into $2 n=58$. This may also be in, some cases, including $H p$, the cause of similarity found between $2 n=58$ (population 9) and $2 n=60$ (population 10) across the broadest, $3000 \mathrm{~m}$, hybrid zone, separating $2 n=$ 58 and 60 . Although here introgression is still conceivable due to the incomplete reproduction isolation. Similarity between $2 n=58$ and northern $2 n=$ 60 populations, might also be, due to selection of similar environments, rather than due to 
introgression which seems the simplest but not always necessarily the true explanatory model. Each case must be analyzed critically and separately to unravel the ensemble of real operational evolutionary forces causing genetic differentiation. Finally, it should be of utmost importance to analyze in depth (restriction mapping, cloning, sequencing, physico-chemical properties), the a and $b$ alleles described here, in an attempt to link structure, mechanism and function with evolutionary history at the molecular-organismal interface underlying adaptation and speciation in the $S$. ehrenbergi superspecies.

Acknowledgements We thank A. Beiles for the statistical analysis. This study was supported by the Israel Discount Bank Chair of Evolutionary Biology, and the Ancell-Teicher Research Foundation for Genetics and Molecular Evolution, established by Florence and Theodore Baumritter of New York, and by NIH grant GM 3757 to N. Maeda.

\section{REFERENCES}

BEN-SHLOMO, R., FIGUEROA, F., KLEIN, J. AND NEVO, E. 1988. Mhc Class II DNA polymorphisms within and between chromosomal species of the Spalax ehrenbergi superspecies in Israel. Genetics, 119, 141-149.

BRUIJN, FI. DE 1984. Remains of the mole rat Microspalax odessanus Topachevsky from Karaburn (Greece, Macedonia) and the family Spalacidae, Paleont. Proc. B, $87,417-425$.

CATZEFLIS, F. M., NEVO, E., AHLQUiST, J. E. AND SIBLEY, C. G. 1988. Relationships of the chromosomal species in the Eurasian mole-rats of the Spalax ehrenbergi group, as determined by DNA-DNA hybridization, and an estimate of the spalacid-murid divergence time. J. Mol. Evol. (In Press).

FEINBERG, A. P. AND VOGLESTEIN, B. 1984. A technique for radiolabeling DNA restriction endonuclease fragments to high specific activity. Anal. Bioch., 137, 266-267.

holland, 1. B. (Course Director) 1983. Basic Cloning Techniques: Course Manual. University of Leicester, Leicester, United Kingdom.

KLEINSCHMIDT, T., NEVO, E., GOODMAN, M. AND BRAUNITZER, G. 1985. Mole rat hemoglobin: Primary structure and evolutionary aspects in a second karyotype of Spalax ehrenbergi, Rodentia $(2 n=52)$. Biol. Chem. Hoppe-Seyler 366 , 679-685.

KUROSKY, A., KIM, H-H. AND TOUCHSTONE, B. 1976. Comparative sequence analysis of the $\mathrm{N}$-terminal region of rat, rabbit and dog Haptoglobin $\beta$-chains. Comp. Biochem. Physiol., 55B, 453-459.

MAEDA, N., YANG, F., BARNETT, D. R., BOWMAN, B. H. ANID SMITHIES, O. 1984. Duplication within the haptoglobin $H p^{2}$ gene. Nature, 309, 131-135.

MAEDA, N., ANI SMITHIES, O. 1986. The evolution of multigene families: Human haptoglobin genes. Ann. Rev. Genet., 20,81-108.
NEI, M. 1972. Genetic distance between populations. Am. Nat., $106,283-292$.

NEI, M. 1973. Analysis of gene diversity in subdivided populations. Proc. Natl. Acad. Sci. U.S.A., 70, 3321-3323.

NEVO, Ł. 1982. Speciation in subterranean mammals. In Barigozzi, C., (ed.) Mechanisms of Speciation, Alan R. Liss, New York, pp. 191-218.

NEVO, E. 1985. Speciation in action and adaption in subterranean mole rats: Patterns and theory. Boll. Zool., 52, 65-95.

NEVO, E. 1986a. Mechanisms of adaptive speciation at the molecular and organismal levels. In Karlin, S. and Nevo, E. (eds) Evolutionary Processes and Theory, Academic Press, New York, pp. 439-474.

NEVO, E. 1986 b. Evolutionary behavior genetics in active speciation and adaptation of fossorial mole rats. Acad. Naz. Lincei, 259, 39-109.

NEVO, F. 1989. Modes of speciation: The nature and role of peripheral isolates in the origin of species. In Giddings, L. V., Kaneshiro and Anderson, W. W. (eds.) Genetics, Speciation and the Founder Principle. Oxford University Press, Oxford. (In Press).

NEVO, E. AND CLEVE, H. 1978. Genetic differentiation during speciation. Nature, 275, 125-126.

NEVO, E. AND SARICH, V. 1974. Immunology and evolution in the mole rat, Spalax ehrengergi, Isr. J. Zool., 23, 210-211.

NEvo, E., BeIles, A. AND BEN-SHLOMO, R. 1984. The evolutionary significance of genetic diversity: Ecological, demographic and life history correlates. in Mani, G. S., (ed.) Evolutionary Dynamics of Genetic Diversity. Lect. Notes Biomath. 53, 13-213.

NEVO, E., HETH, G., AND BEILES, A. 1982. Differential survivorship of evolving chromosomal species of mole rats, Spalax: An unplanned laboratory experiment. Evolution, 36, 13151317.

NEVO, F., JOH, K., HORI, K. AND BEILES, A. 1988. Aldolase DNA polymorphism in subterranean mole rats: Genetic differentiation and environmental correlates (Submitted).

RAUGEI, G., BENSI, G., COLANTUONI, V., ROMANO, V. AND SANTORO, C. 1983. Sequence of human haptoglobin cDNA: Evidence that the $\alpha$ and $\beta$ subunits are coded by the same mRNA. Nucleic Acids Res., 11, 5811-19.

SOUTHERN, E. M. 1975. Detection of specific sequences among DNA fragments separated by gel electrophoresis. $J$. Mol Biol., 98, 503-517.

SUZUKI, H., MORIWAKI, K. AND NEVO, E. 1987. Ribosomal DNA (rDNA) spacer polymorphism in mole rats. Mol Biol. Evol., 4, 602-610.

VAN DER STRATEN, A., HERZOG, A., JACOBS, P., CABEZON, T. AND BOLLEN, A. 1983. Molecular cloning of human haptoglobin cDNA: Evidence for a single mRNA coding for $\alpha^{2}$ and $\beta$ chains. Embo J., 2, 1003-1007.

TCHERNOV, E. 1968. Succession of rodent faunas during the Upper Pleistocene in Israel. In Parey, P. (ed.) Mammalian depicta Hamburg and Berlin.

TCHERNOV, E. 1987. The age of the 'Ubeidiya formation', an Early Pleistocene Hominid site in the Jordan Valley, Israel. Isr. J. Zool., 36, 3-30.

YANG, F., BRUNE, J. L., BALDWIN, W. D., BARNETT, D. R. AND BOWMAN, B. H. 1983. Identification and characterization of human haptoglobin cDNA. Proc. Natl. Acad. Sci. U.S.A., $80,5875-5879$. 